\title{
Early Algebraic Thinking: Epistemological, Semiotic, and Developmental Issues
}

\author{
Luis Radford
}

\begin{abstract}
In this article I present some findings of an ongoing 5-year longitudinal research program with young students. The chief goal of the research program is a careful and systematic investigation of the genesis of embodied, non-symbolic algebraic thinking and its progressive transition to culturally evolved forms of symbolic thinking. The investigation draws on a cultural-historical theory of teaching and learning - the theory of objectification - that emphasizes the sensible, embodied, social, and material dimension of human thinking and that articulates a cultural view of development as an unfolding dialectic process between culturally and historically constituted forms of mathematical knowing and semiotically mediated classroom activity.
\end{abstract}

Keywords Sensuous cognition • Vygotsky • Arithmetic versus algebraic thinking

\section{Introduction}

In light of the legendary difficulties that the learning of algebra presents to students, it has been suggested that a progressive introduction to algebra in the early grades may facilitate students' access to more advanced algebraic concepts later on (Carraher and Schliemann 2007). An early development of algebraic thinking may, in particular, ease students' contact with algebraic symbolism (Cai and Knuth 2011).

The theoretical grounding of this idea and its practical implementation remain, however, a matter of controversy. Traditionally, algebra has been taught only after students have had the opportunity to acquire a substantial knowledge of arithmetic.

\footnotetext{
L. Radford ( $\square)$

Université Laurentienne, Ontario, Canada

e-mail: Lradford@laurentian.ca

(C) The Author(s) 2015 
That is, arithmetic thinking has been assumed to be a prerequisite for the emergence and development of algebraic thinking. Clearly, an introduction to algebra in the early grades does not conform to such an assumption. Now, if this is so, if algebra needs not to come after arithmetic, the question is: What is the difference and relationship between these two disciplines? Evading these questions does not do us any favours.

In the next section, I briefly discuss the question of the relationship between algebra and arithmetic. Drawing on historical and educational research, I suggest an epistemological distinction between the forms of thinking that are required in both disciplines. Then, I present some findings of a 5-year longitudinal classroom research program where 8-year old students were followed as they moved from Grade 2 to Grade 6. I shall focus in particular on the genesis and development of embodied, non-symbolic algebraic thinking and its progressive transition to cultural forms of symbolic thinking.

\section{Arithmetic and Algebra: Filiations and Ruptures}

The question of the filiations and ruptures between arithmetic and algebra was one of the major educational research themes in the 1980s and 1990s. This question was at the heart of several research programs. It was often discussed in various PME's Working Groups and research reports (Bednarz et al. 1996; Sutherland et al. 2001).

Filloy and Rojano's (1989) work points to one of the fundamental breaks between arithmetic and algebra-what they call a cut. This cut was observed in clinical studies where students faced equations of the form $\mathrm{Ax}+\mathrm{B}=\mathrm{Cx}+\mathrm{D}$. To solve equations of this form, the arithmetic methods of "reversal operations"which are effective to solve equations of the type $\mathrm{Ax}+\mathrm{B}=\mathrm{D}$ (the students usually subtract B from D and divide by A) — are no longer applicable. The students have to resort to a truly algebraic idea: to operate on the unknown. In order to operate on the unknown, or on indeterminate quantities in general (e.g., variables, parameters), one has to think analytically. That is, one has to consider the indeterminate quantities as if they were something known, as if they were specific numbers (see, e.g., Kieran 1989, 1990; Filloy et al. 2007). From a genetic viewpoint, this way of thinking analytically — where unknown numbers are treated on a par with known numbers-distinguishes arithmetic from algebra. And it is so characteristic of algebra that French mathematician François Viète (one of the founders of modern symbolic algebra) identified algebra as an analytic art (Viète 1983).

A consequence of this difference between arithmetic and algebra is the following. Because of algebra's analytic nature, formulas in algebra are deduced. Failing to notice this central analytic characteristic of algebra may lead us to think that the production of formulas in patterns (regardless of how they were produced) is a symptom of algebraic thinking. But as Howe (2005) notes, producing a formula 
might merely be a question of guessing the formula and trying it. I completely agree with him that there is nothing algebraic in trying and guessing. Try-and-guess strategies are indeed based on arithmetic concepts only.

Epistemological research has also made a contribution to the conversation about the distinction between arithmetic and algebra. This research suggests that the difference between these disciplines cannot be cast in terms of notations, as it has often been thought. The alphanumeric algebraic symbolism that we know today is indeed a recent invention. In the west it appeared during the Renaissance, along with other forms of representation, like perspective in painting and space representation, underpinned by changes in modes of production and new forms of labour division. The birth of algebra is not the birth of its modern symbolism. In his Elements, Euclid resorted to letters without mobilizing algebraic ideas. Ancient Chinese mathematicians mobilized algebraic ideas to solve systems of equations without using notations. Babylonian scribes used geometric diagrams to think algebraically. As a result, the use of letters in algebra is neither a necessary nor a sufficient condition for thinking algebraically. Naturally, our modern algebraic symbolism allows us to carry out transformations of expressions that may be difficult or impossible with other forms of symbolism. However, as we shall see in a moment, the rejection of the idea that notations are a manifestation of algebraic thinking, opens up new avenues to the investigation of elementary forms of algebraic thinking in young students.

\section{Some Background of the Research}

The investigation of young students' algebraic thinking that I report here started in 2007. The decade before, I was interested in investigating adolescent and young adults' algebraic thinking. From 1998 to 2006 I had the opportunity to follow several cohorts of students from Grade 7 until the end of high school. Like many of my colleagues, I started focusing on symbolic algebra, that is, an algebraic activity mediated by alphanumeric signs. One of my goals was to understand the processes students undergo in order to build symbolic algebraic formulas. My working hypothesis was that in order to understand the manner in which students bestow meaning to alphanumeric expressions, we should pay attention to language (Radford 2000). However, during the analysis of hundreds of hours of videotaped lessons, it became apparent that our students were not resorting only to language, but also to gestures, and other sensuous modalities in ways that were far from mere byproducts of interaction. It was clear that gestures and other embodied forms of action were an integral part of the students' signifying process and cognitive functioning. The problem was to come up with suitable and theoretically articulated explanatory principles, in order to provide an interpretation of the students' algebraic thinking that would integrate those embodied elements that the video analyses put into evidence. Although by the early 2000s, some linguists and cognitive psychologists had developed interesting work around the question of embodiment 
(Lakoff and Núñez 2000), their accounts were not easy to apply to such complex settings as classrooms; nor were they necessarily taking into account the historical and cultural dimension of knowledge. In the following years, with the help of some students and collaborators, I was able to refine our theoretical approach and reveal non-conventional, embodied forms of algebraic thinking (Radford 2003). In Radford et al. (2007), we reported a passage in which Grade 9 students displayed an amazing array of sensuous modalities to come up with an algebraic formula in a pattern activity. What is amazing in the reported passage is the subtle coordination of words, written signs, drawn figures, gestures, perception, and rhythm. Figure 1 presents an interesting series of gestures that a student makes while trying to perceive a mathematical structure behind the sequence. Focusing on the first term of the sequence (which is shown in the three first pictures of Fig. 1), Mimi, the student, points with her index to the first circle on the top row and says "one;" she moves the finger to the first circle on the bottom row and repeats "one." Then she moves the index to her right and makes a kind of circular indexical gesture to point to the three remaining circles, while saying "plus three." She starts again the same series of gestures, this time pointing to the second term of the sequence (see second term in Pic 4 of Fig. 1), saying now "two, two plus three." She restarts the same series of gestures in dealing with the third term (see third term of the sequence in Fig. 1, Pic 4; we have added dashed lines to the terms of the sequence to indicate the circles that Mimi points to as she makes her gestures). In doing so, Mimi reveals an embodied formula that, instead of being made up of letters, is made up of words and gestures: the formula is displayed in concreto: "one, one, plus three; two, two plus three; three, three, plus three." She then applied the formula to Term 10 (which was not drawn and had to be imagined): "you will have 10 dots [i.e., circles] (she makes a gesture on the desk to indicate the position of the circles), 10 dots (she makes a similar gesture), plus 3." The embodied formula rests on a use of variables and functional relations that conform to the requirement of analyticity that, as I suggested previously, is characteristic of algebra. Although the variable 'number of the term' is not represented through a letter, it appears embodied in its surrogates - the particular numbers the variable takes. The formula is then shown as the series of calculations on the instantiated variable. And, as such, the formula is algebraic. Now, our Grade 9 students did use alphanumeric symbolism and built the formula " $n+n+3$," which was then transformed into " $n \times 2+3$ " (Radford et al. 2007). Hence, these Grade 9 students went unproblematically from an embodied form of thinking to a symbolic one.

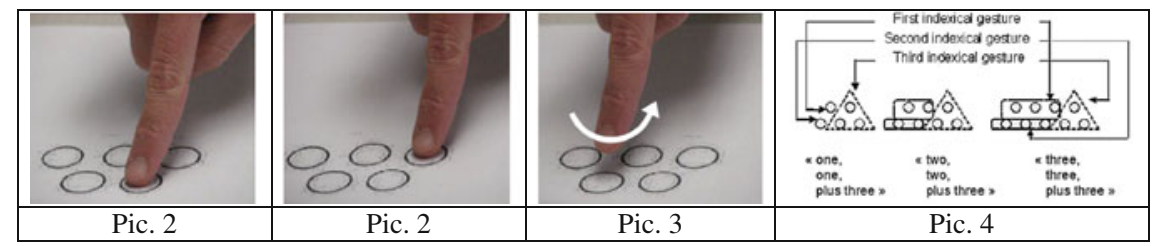

Fig. 1 A Grade 9 student displaying an impressive multimodal coordination of semiotic resources. Recostructed from the video 
We came back to other published and unpublished analyses and noticed that the subtle multimodal coordination of senses and signs was a widespread phenomenon in adolescents. Then arose a research question that has kept me busy for the past 6 years: would similar embodied forms of algebraic thinking be accessible to young students? And if yes, how would these embodied forms of thinking develop as the students moved from one grade to the next? As Grade 2 students are still learning to read and write in Ontario, Grade 2 looked like a good place to start. This is how I moved to a primary school and embarked on a new longitudinal research.

\section{Grade 2: Young Students' Non-symbolic Algebraic Thinking}

The first generalizing activity in our Grade 2 class was based on the sequence shown in Fig. 2.

We asked the students to extend the sequence up to Term 6. In subsequent questions, we asked them to find out a procedure to determine the number of rectangles in Terms 12 and 25. Figure 3 shows the answers provided by two students: Carlos and James.

Contrary to what we observed in our research with adolescent students, in extending the sequence, most of our Grade 2 students focused on the numerical aspect of the terms only. Counting was the leading activity. Generally speaking, to extend a figural sequence, one needs to grasp a regularity that involves the linkage of two different structures: one spatial and the other numerical. From the spatial structure emerges a sense of the rectangles' spatial position, whereas their numerosity emerges

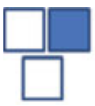

Term 1

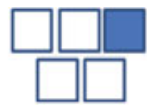

Term 2

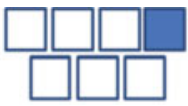

Term 3

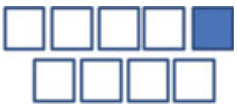

Term 4

Fig. 2 The first terms of a sequence that Grade 2 students investigated in an algebra lesson

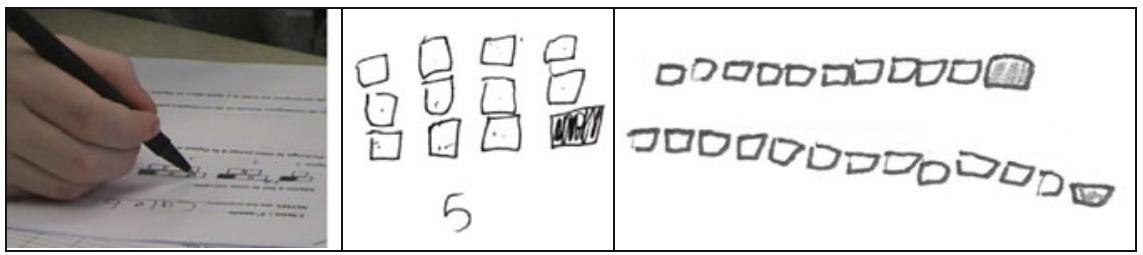

Fig. 3 To the left, Carlos, counting aloud, points sequentially to the squares in the top row of Term 3. In the middle, Carlos' drawing of Term 5. To the right, James' drawing of Terms 5 (top) and 6 (bottom) 
from a numerical structure. While Carlos attends to the numerical structure in the generalizing activity, the spatial structure is not coherently emphasized. This does not mean that Carlos, James and the other students do not see the figures as composed of two horizontal rows. What this means is that the emphasis on the numerical structure somehow leaves in the background the geometric structure. We could say that the shape of the terms of the sequence is used to facilitate the counting process. Thus, as picture 1 in Fig. 3 shows, Carlos always counted the rectangles in a spatial orderly way. The geometric structure, however, does not come to be related to the numerical one in a meaningful and efficient way. It is not surprising within this context, then, that the students encountered difficulties in answering our questions about Terms 12 and 25. Without resorting to an efficient way of counting, the counting process of rectangles one-by-one in remote terms beyond the perceptual field became extremely difficult.

Because of their spatial connotation, it might not be surprising that, in extending the sequences, our young students did not use deictic terms, like "bottom" or "top." In the cases in which the students did succeed in linking the spatial and numerical structures, the spatial structure appeared only ostensibly, i.e., "top" and "bottom" rows were not part of the students' discourse but were made apparent through pointing and actual row counting: they remained secluded in the embodied realm of action and perception. The next day, the teacher discussed the sequence with the students and referred to the rows in an explicit manner to bring to the students' attention the linkage of the numerical and spatial structures. To do so, the teacher drew the first five terms of the sequence on the blackboard and referred to an imaginary student who counted by rows. "This student," she said to the class, "noticed that in Term 1 (she pointed to the name of the term) there is one rectangle on the bottom (and she pointed to the rectangle on the bottom), one on the top (pointing to the rectangle), plus one dark rectangle (pointing to the dark rectangle)." Next, she moved to Term 2 and repeated in a rhythmic manner the same counting process, coordinating the spatial deictics "bottom" and "top," the corresponding spatial rows of the figure, and the number of rectangles therein. To make sure that everyone was following, she started again from Term 1 and, at Term 3, she invited the students to join her in the counting process, going together up to Term 5 (see Fig. 4).

Then, the teacher asked the class about the number of squares in Term 25. Mary raised her hand and answered: " 25 on the bottom, 25 on top, plus 1." The class
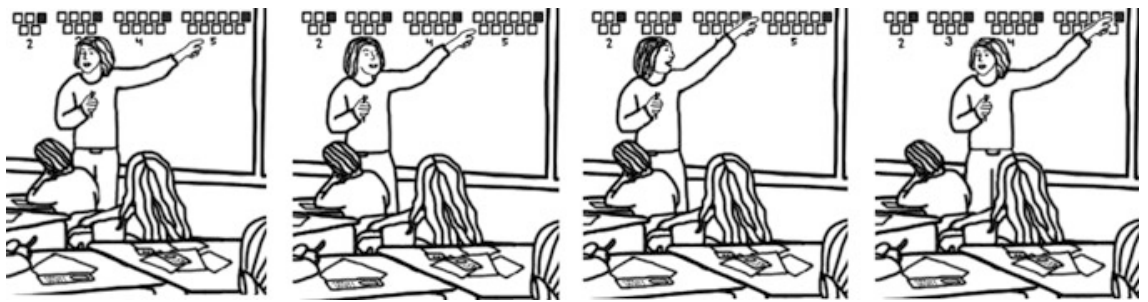

Fig. 4 The teacher and the students counting rhythmically say (see Pic 1) "Term 5", (Pic 2) "5 on the bottom", (Pic 3) "5 on top", (Pic 4) "plus 1." 


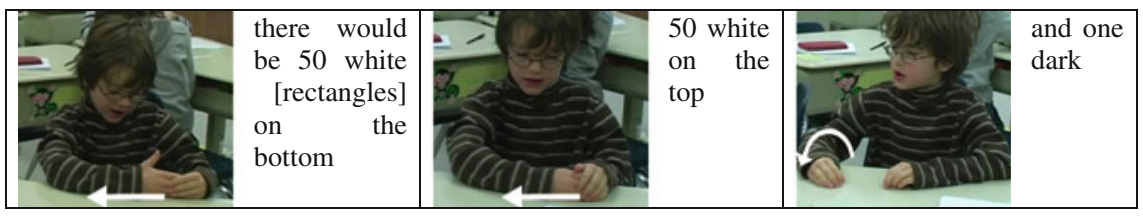

Fig. 5 Karl explaining Term 50

spent some time dealing with "remote" terms, such as Terms 50 and 100. Figure 5 shows Karl explaining to the teacher and his group-mates what Term 50 looks like.

In picture 1, Karl moves his arm and his body from left to right in a vigorous manner to indicate the bottom row of Term 50, while saying that there would be 50 white rectangles there. He moves his arm a bit further and repeats the moving armgesture to signify the top row of Term 50 . Then he makes a semi-circle gesture in the air to signify the dark square.

The students played for a while with remote terms. In Karl's group, one of the questions revolved around Term 500 and Term 50:

Karl How about doing 500 plus 500?

Erica No. Do something simpler

Karl (Talking almost at the same time) 500 plus 500 equals 1000

Erica plus 1, 1001

Karl plus 1 , equals 1001

Cindy (Talking about Term 50) 50 plus 50, plus 1 equals 101

Schematically speaking, the students' answer to the question of the number of rectangles in remote particular terms was " $\mathrm{x}+\mathrm{x}+1$ " (where $\mathrm{x}$ was always a specific number). The formula, I argue, is algebraic in nature, even if it is not expressed in standard notations. In this case, indeterminacy and analyticity appear in an intuited form, rather than explicitly. A natural question is: Is this all that Grade 2 students are capable of? In fact, the answer is no. As we shall see in the next section, we were able to create conditions for the emergence of more sophisticated forms of algebraic thinking.

\section{Beyond Intuited Indeterminacy: The Message Problem}

On the fifth day of our pattern generalization teaching-learning sequence, the teacher came back to the sequence from the first day (Fig. 2). To recapitulate, she invited some groups to share in front of the class what they had learned about that sequence in light of previous days' classroom discussions and small group work. Then, she asked a completely new question to the class. She took a box and, in front of the students, put in it several cards, each one having a number: 5, 15, 100, 104, etc. Each one of these numbers represented the number of a term of the sequence shown in 
Fig. 2. The teacher invited a student to choose randomly one of the cards and put it into an envelope, making sure that neither the student herself nor the teacher nor anybody else saw the number beforehand. The envelope, the teacher said, was going to be sent to Tristan, a student from another school. The Grade 2 students were invited to send a message that would be put in the envelope along with the card. In the message the students would tell Tristan how to quickly calculate the number of rectangles in the term indicated on the card. The number of the term was hence unknown. Would the students be able to generalize the embodied formula and engage with calculations on this unknown number? In other terms, would our Grade 2 students be able to go beyond intuited indeterminacy and its corresponding elementary form of algebraic thinking? As in the previous days, the students worked in small groups of three. The usual response was to give an example. For instance, Karl suggested: "If the number [on the card] is 50, you do 50, plus 50, plus 1." The teacher commended the students for the idea, but insisted that the number could be something else and asked if there would be another way to say it without resorting to examples. After an intense discussion, the students came up with a suggestion:

Erica It's the number he has, the same number at the bottom, the same number at the top, plus $1 \ldots$

Teacher That is excellent, but don't forget: he doesn't have to draw [the term]. He just has to add... So, how can we say it, using this good idea?

Erica We can use our calculator to calculate!

Teacher Ok. And what is he going to do with the calculator?

Erica He will put the number... (she pretends to be inserting a number into the calculator)... plus the same number, plus 1 (as she speaks, she pretends to be inserting the number again, and the number 1).

Another group suggested "twice the number plus 1." Naturally, the use of the calculator is merely virtual. In the students' real calculator, all inputs are specific numbers. Nevertheless, the calculator helped the students to bring forward the analytic dimension that was apparently missing in the students' explicit formula. Through the virtual use of the calculator, calculations are now performed on this unspecified instance of the variable - the unknown number of the figure.

Let me summarize our Grade 2 students' accomplishments during the first week that they were exposed to algebra. In the beginning, most of our students were dealing with figural sequences like the one in Fig. 1 through a focus on numerosity. Finding out the number of elements (rectangles, in the example here discussed) in remote terms was not easy. The joint counting process in which the teacher and students engaged during the second day helped the students to move to other ways of seeing sequences. The joint counting process made it possible for the students to notice and articulate new forms of mathematical generalization. In particular, they became aware of the fact that the counting process can be based on a relational idea: to link the number of the figure to relevant parts of it (e.g. the squares on the bottom row). This requires an altogether new perception of the number of the term and the terms themselves. The terms appear now not as a mere bunch of ordered 
rectangles but as something susceptible to being decomposed, the decomposed parts bearing potential clues for algebraic relationships to occur. Interestingly enough, historically speaking, the "decomposition" of geometric figures in simpler forms (e.g., straight lines) was systematically developed in the 17 th century by Descartes in his Geometry, a central book in the development of algebraic ideas. The decomposition of figures permitted the creation of relationships between known and unknown numbers and the carrying out of calculations on them "without making a distinction between known and unknown [parts]" (Descartes 1954, p. 8). Our examples - as well as those reported by other researchers with other Grade 2 students - suggest that the linkage of spatial and numerical structures constitutes an important aspect of the development of algebraic thinking. Such a linkage rests on the cultural transformation in the manner in which sequences can be seen - a transformation that may be termed the domestication of the eye (Radford 2010). For the modern mathematician's eye, the complexity behind the perception of simple sequences like the one our Grade 2 students tackled remains in the background, to the extent that to see things as the mathematician's eye does, ends up seeming natural. However, as our results intimate, there is nothing natural there. To successfully attend to what is algebraically meaningful is part of learning to think algebraically. This cultural transformation of the eye is not specific to Grade 2 students. It reappears in other parts of the students' developmental trajectory. It reappears, later on, when students deal with factorization, where discerning structural syntactic forms become a pivotal element in recognizing common factors or prototypical expressions.

All in all, the linkage of spatial and numerical structures resulted, as we have seen, in the emergence of an elementary way of algebraic thinking that manifested itself in the embodied constitution of a formula where the variable is expressed through particular instances, which we can schematize as " $\mathrm{x}+\mathrm{x}+1$ " (where $\mathrm{x}$ was always a specific number). This formula, I argued on semiotic and epistemological grounds, is genuinely algebraic. That does not mean that all formulas provided by young students are algebraic. To give an example, one of the students suggested that to find out the number of elements in Term 100, you keep adding 2, and 2 and 2 to Term 1 until you get to Term 100. This is an example of arithmetic generalization - not of an algebraic one, as there is no analyticity involved. The "Message Problem" offered the students a possibility to go beyond intuitive indeterminacy and to think, talk, and calculate explicitly on an unknown number. Although several students were able to produce an explicit formula (e.g., "the number plus the number, plus 1" or "twice the number plus 1"), other students produced a formula where the general unknown number was represented through an example. This is what Mason (1996) calls seeing the general in or through the particular. Both the explicit formula and the general-through-the-particular formula bear witness to a more sophisticated form of elementary algebraic thinking than the embodied one where the variable and the formula are displayed in action.

Revealing our Grade 2 students' aforementioned elementary, pre-symbolic forms of algebraic thinking responded to our first research question-i.e., whether the embodied forms of thinking that we observed in adolescents are accessible to 
younger students. Yet, there are differences. Adolescents in general tend to gesture, talk and symbolize in harmonious coordinated manners (often after a period of mismatch between words and gestures (Arzarello and Edwards 2005; Radford 2009a). Our young students, in contrast, tend to gesture with energetic intensity (see e.g. Fig. 5). The energetic intensity may decrease as the students become more and more aware of the variables and the relationship between known and unknown numbers. However, the energetic intensity remains relatively pronounced as compared to what we have seen in adolescents (Radford 2009a, b). This phenomenon may be a token of a problem related to our second research question, namely: How does young students' algebraic thinking develop?

Developmental questions are very tricky, as psychologists know very well. It is not enough to collect data year after year and merely compare what students did in Year 1, to what they did in Year 2, etc. Exposing differences shows something but does not explain anything. I struggled with the question of the development of students' mathematical thinking for about a decade when I was doing research with adolescents, and I have to confess that I was unable to come up with something satisfactory. Yet, my research with adolescents helped me to envision a sensuous and material conception of mathematical cognition (Radford 2009b) that was instrumental in tackling the developmental question. Before going further in my account of what the students did in the following years, I need to dwell on the question of development first.

\section{Thinking and Its Development}

In contrast to mental cognitive approaches, thinking, I have suggested (Radford 2009 b), is not something that solely happens 'in the head.' Thinking may be considered to be made up of material and ideational components: it is made up of (inner and outer) speech, objectified forms of sensuous imagination, gestures, tactility, and our actual actions with cultural artifacts. Thus, in Fig. 5, for instance, Karl is thinking with and through the body in the same way that he $i$ s thinking through and in language and the arsenal of conceptual categories it provides for us to notice, highlight, and attend to things, and intend them in certain cultural topical ways. The same can be said of the teacher in Fig. 4. Although it might be argued that the teacher and the student are merely communicating ideas, I would retort that this division between thinking and communicating makes sense only within the context of a conception of the mind as a private space within us, where ideas are created, computed and only then communicated. This computational view of the mind has a long history in our Western idealist and rationalist philosophical traditions. The view that I am sketching here goes against the dualistic assumption of mind versus body or ideal versus material. Thinking appears here as a an idealmaterial form of reflection and action, which does not occur solely in the head but also in and through a sophisticated semiotic coordination of speech, body, gestures, symbols and tools. This is why, during difficult conversations, rather than digging 
in the head first to find the ideas that we want to express, we hear ourselves thinking as we talk, and realize, at the same time as our interlocutors, what we are thinking about.

Now to say that thinking is made up of (inner and outer) speech, objectified forms of sensuous imagination, gestures, tactility, and our actual actions with cultural artifacts does not mean that thinking is a collection of items. If we come back to our examples, Carlos (see Fig. 3, left), while moving the upper part of his body, was resorting to pointing gestures and words to count the rectangles in the first terms of the sequence. Words and gestures were guiding his perceptual activity to deal with the numerosity of the terms. Like Carlos, Karl moved his upper body, made arm- and hand-gestures and resorted to language (Fig. 5). In stating the formula "the number plus the number, plus 1," Erica gestured as if she was pressing keys in the calculator keyboard (Radford 2011). Yet, the relationship between perception, gestures and words is not the same. What it means is that thinking is not a mere collection of items. Thinking is rather a dynamic unity of material and ideal components. This is why the same gesture (e.g. an indexical gesture pointing to the rectangles on top of Term 3) may mean something conceptually sophisticated or something very simple. That is, the real significance of a component of thinking can only be recognized by the role such a component plays in the context of the unity of which it is a part.

Now I can formulate my developmental question. If thinking is a systemic unity of ideational and material components, it would be wrong to study its development by focusing on one of its components only. Thus, the development of algebraic thinking cannot be reduced to the development of its symbolic component (notation use, for instance). The development of algebraic thinking must be studied as a whole, by taking into account the interrelated dialectic development of its various components (Radford 2012). If in a previous section I talked about the 'domestication of the eye,' this domestication has to be related to the 'domestication of the hand' as well. And, indeed, this is what happened in our Grade 2 class from the second day on. As we recall, the teacher (Fig. 4) made extensive use of gestures and an explicit use of rhythm, and linguistic deictics, followed later by the students, who started using their hands and their eyes in novel ways, opening up new possibilities to use efficient and evolved cultural forms of mathematical generalization that they successfully applied to other sequences with different shapes.

To sum up, it is not only the tactile, the perceptual, or the symbol-use activity that is developmentally modified. In the same way as perception develops, so do speech (e.g., through spatial deictics) and gesture (through rhythm and precision). Perception, speech, gesture, and imagination develop in an interrelated manner. They come to form a new unity of the material-ideational components of thinking, where words, gestures, and signs more generally, are used as means of objectification, or as Vygotsky (Vygotsky 1987), p. 164 put it, "as means of voluntary directing attention, as means of abstracting and isolating features, and as a means of [...] synthesizing and symbolising". Within this context, to ask the question of the development of algebraic thinking is to ask about the appearance of new systemic structuring relationships between the material-ideational components of thinking 
(e.g., gesture, inner and outer speech) and the manner in which these relationships are organized and reorganized. It is through these developmental lenses that I studied the data collected in the following years and that I summarize in the rest of this article, focusing on Grades 3 and 4.

\section{Grade 3: Semiotic Contraction}

As usual, in Grade 3 the students were presented with generalizing tasks to be tackled in small groups. The first task featured a figural sequence, $S_{n}$, having $n$ circles horizontally and $n-1$ vertically, of which the first four terms were given. Contrary to what he did first in Grade 2, from the outset, Carlos perceived the sequence taking advantage of the spatial configuration of its terms. Talking to his teammates about Term 4 he said: "here (pointing to the vertical part) there are four. Like you take all this [i.e., the vertical part] together (he draws a line around), and you take all this [i.e., the horizontal part] together (he draws a line around; see Fig. 6, pic 1). So, we should draw 5 like that (through a vertical gesture he indicates the place where the vertical part should be drawn) and (making a horizontal gesture) 5 like that" (see Fig. 6, pics 2-3).

When the teacher came to see the group, she asked Carlos to sketch for her Term 10, then Term 50. The first answer was given using unspecified deictics and gestures. He quickly said: "10 like this (vertical gesture) and 10 like that" (horizontal gesture). The specific deictic term "vertical" was used in answering the question about Figure 50. He said: "50 on the vertical... and 49..." When the teacher left, the students kept discussing how to write the answer to the question about Term 6. Carlos wrote: "6 vertical and 5 horizontal."

In developmental terms, we see the evolution of the unity of ideational-material components of algebraic thinking. Now, Carlos by himself and with great ease coordinates gestures, perception, and speech. The coordination of these outer components of thinking is much more refined compared to what we observed in Grade 2. This refinement is what we have called a semiotic contraction (Radford 2008a), that is, a genetic process in the course of which choices are made between what counts as relevant and irrelevant; it leads to a contraction of previous semiotic
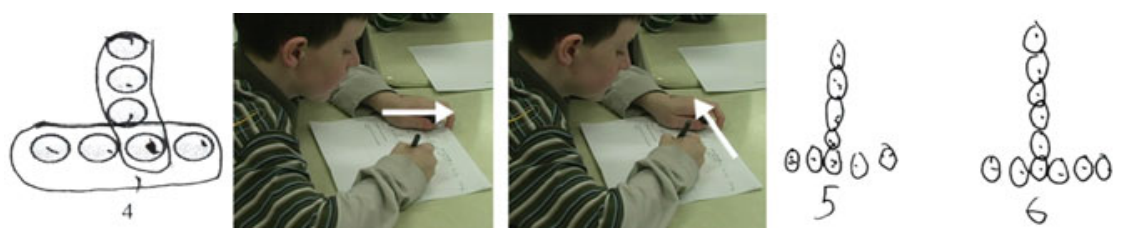

Fig. 6 To the left, Term 4 of the given sequence. Middle, Carlos's vertical and horizontal gestures while imagining and talking about the still to be drawn Term 5. To the right, Carlos's drawings of Terms 5 and 6 
activity, resulting in a more refined linkage of semiotic resources. It entails a deeper level of consciousness and intelligibility of the problem at hand and is a symptom of learning and conceptual development.

\section{Grade 4: The Domestication of the Hand}

To check developmental questions, in Grade 4 we gave the students the sequence with which they started in Grade 2 (see Fig. 2). This time, from the outset, Carlos perceived the terms as being divided into two rows. Talking to his teammates and referring to the top row of Term 5, he said as if talking about something banal: "5 white squares, 'cause in Term 1, there is 1 white square (making a quick pointing gesture)... Term 2, 2 [squares] (making another quick pointing gesture); 3, (another quick pointing gesture) 3." He drew the five white squares on the top row of Term 5 and added: "after that you add a dark square." Then, referring to the bottom row of Term 4: "there are 4; there [Term 5] there are 5." When the teacher came to see their work, Carlos and his teammates explained "We looked at Term 2, it's the same thing [i.e., 2 white squares on top]... Term 6 will have 6 white squares."

There was a question in the activity in which the students were required to explain to an imaginary student (Pierre) how to build a big term of the sequence (the "Big Term Problem"). In Grade 2, the students chose systematically a particular term. This time, Carlos wrote: "He needs [to put as many white squares as] the number of the term on top and on the bottom, plus a dark square on top."

\section{The “Message Problem" Again}

At the end of the lesson, the students tackled the "Message Problem" again. As opposed to the lengthy process that, in Grade 2, preceded the building of a message without particular examples (Radford 2011), this time the answer was produced quicker:

David The number of the term you calculate twice and add one. That's it! Carlos (Rephrasing David's idea) twice the number plus one

The activity finished with a new challenge. The teacher asked the students to add to the written message a "mathematical formula." After a discussion in Carlos's group concerning the difference between a phrase and a mathematical formula, the students agreed that a formula should include operations only. Carlos's formula is shown in pic 3 of Fig. 7.

From a developmental perspective, we see how Carlos's use of language has been refined. In Grade 2 he was resorting to particular terms (Term 1,000) to answer the same question about the "big term." Here he deals with indeterminacy in an 

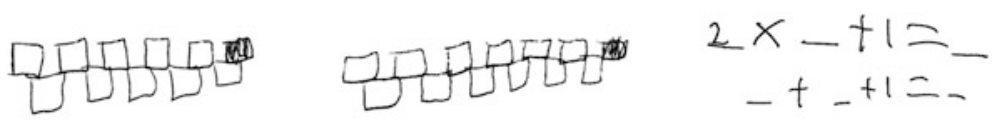

Fig. 7 Left, Carlos' drawings of Terms 5 and 6. Right, Carlos's formulas

easy way, through the expression "the number of the term." He even goes further and produces two symbolic expressions to calculate the total of squares in the unspecified term (Fig. 7, right). The semiotic activities of perceiving, gesturing, languaging, and symbolizing have developed to a greater extent. They have reached an interrelational refinement and consistency that was not present in Grade 2 and was not fully developed in Grade 3. This cognitive developmental refinement became even more apparent when the teacher led the students to the world of notations, as we shall now see.

\section{The Introduction to Notations}

The introduction to notations occurred when the students discussed their answers to homework based on the sequence shown in Fig. 8. The discussion took place right after the general discussion about the "Message Problem" alluded to in the previous sub-section.

The teacher gave the students the opportunity to compare and discuss their answers to the homework by working in small groups. In Carlos' group, the terms of the sequence were perceived as made up of two rows, each one having the same number as the number of the term plus an addition of two squares at the end (see pic 2 in Fig. 8). As Carlos suggests, referring to Term 15, "15 on top, 15 at the bottom, plus 2, that is 32." Or alternatively, as Celia, one of Carlos' teammates, explains, " $15+1$ equals 16 , then $16+16 \ldots$ which makes 32 ." After about 10 min of smallgroup discussion, the teacher encouraged the students to produce a formula like the one that they just provided for the "Message Problem." Then, the class moved to a general discussion where various groups presented their findings. Erica went to the Interactive White Smart Board (ISB) and suggested the following formula: " $1+1+2 x_{-}=\ldots$ - The teacher asked whether it would be possible to write, instead of the underscores, something else. One student suggested putting an

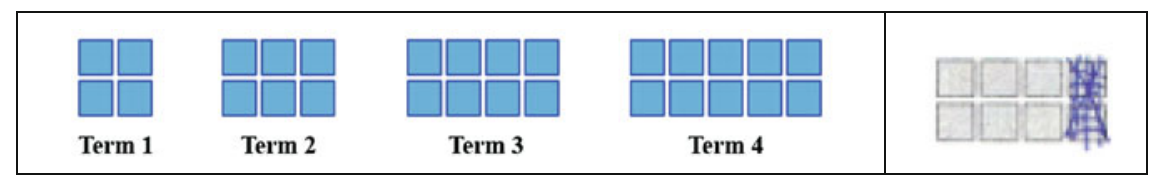

Fig. 8 Pic 1 (left), the sequence of the homework. Pic 2 (right), Carlos' decomposition of Term 3 
interrogation mark. The teacher acknowledged that interrogation mark could also be used, and asked for other ideas. Samantha answered with a question:

Samantha A letter?

Teacher Ah! Could I write one plus one plus two times n? What does n mean? A student A number...

Teacher Could we write that (i.e., one plus one plus two times n) equals n? (Some students answered yes, others no; talking to Erica who is at the whiteboard) Ok. Write it, write your formula (Erica writes $1+1+2 \times n=n)$

Carlos No, because $\mathrm{n}$ (meaning the first one) is not equal to $\mathrm{n}$ (meaning the second one)

Teacher Ah! Why do you say that $\mathrm{n}$ is not equal to $\mathrm{n}$ ?

Carlos Because if you do 2 times $n$, that will not equal [the second] $n$

Teacher Wow!

In order not to rush the students into the world of notations, the teacher decided to delay the question of using a second letter to designate the total. As we shall see, this question will arise in the next activity. In the meantime, the formula was left as $1+1+2 \times n=$

The next activity started right away. The students were provided with the new activity sheet that featured the sequence shown in Fig. 9. The students were encouraged to come up with as many formulas as possible to determine the number of squares in any term of the sequence.

During the small-group discussion, William offers a way to perceive the terms. Talking to Carlos, and referring to Term 6, which they drew on the activity sheet, William says (talking about the top row): "There are 8 [squares], because $6+2=8$. You see, on the bottom it's always the number of the term, you see?" His utterance is accompanied by a precise two-finger gesture through which he indicates the bottom row (see Fig. 10, left). He continues: "then, on the top, it's always plus 2" (making the gesture shown in Fig. 10, right).

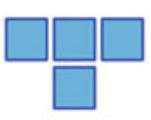

Term 1

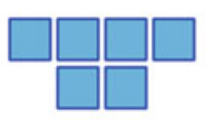

Term 2

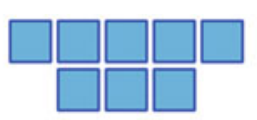

Term 3

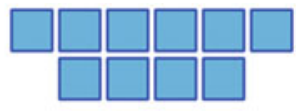

Term 4

Fig. 9 The featured sequence of the new activity
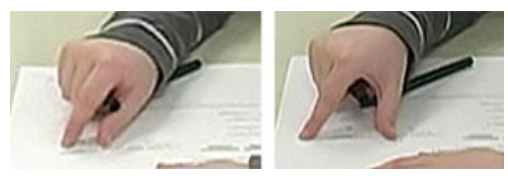

Fig. 10 William making precise gestures to refer to Term 6 
The answer to the "Message Problem" was provided without difficulties. Without hesitation, Carlos said: "Ok. Double the number and add 2." The class moved to a general discussion, which was a space to discuss different forms of perceiving the sequence and of writing a formula. Marianne went to the ISB and suggested that the terms could be imagined as divided into two equal rows and that one square is added to the left and one to the right of the top row. In Fig. 11, referring to Term 3 , she points first to the top row (imagined as made up of three squares; see Fig. 11, Pic 1). Then she points to the bottom row (Pic. 2), then to the extra square at the top right (Pic. 3) and to the extra square at the top left (Pic. 4). Celia proposed that a term was the same as the previous one to which two squares are added at the right end. In Fig. 11, Pic 5 and 6, she hides the two rightmost squares in Terms 2 and 3 to show that what remains in each case is the previous term. The developmental sophistication that the perception-gesture-language systemic unity has achieved is very clear.

Then, the students presented their formulas. Carlos presented the following formula: $\underline{N}+\underline{N}+2=\ldots$. The place for the variable in the formula is symbolized with a letter and the underscore sign. Letters in Carlos's formula appear timidly drawn, still bearing the vestiges of previous symbolizations (see Fig. 7, right).

The teacher asked if it would be possible to use another letter to designate the result:

Teacher Well, we started with letters [in your formula]. Maybe we could continue with letters?

Carlos No!

Teacher Why not?

Carlos An r?

Teacher Why r?

Caleb The answer (in French, la réponse)

Carlos completed the formula as follows: $: \underline{N}+\underline{N}+2=\underline{R}$. Other formulas were provided, as shown in Fig. 12:

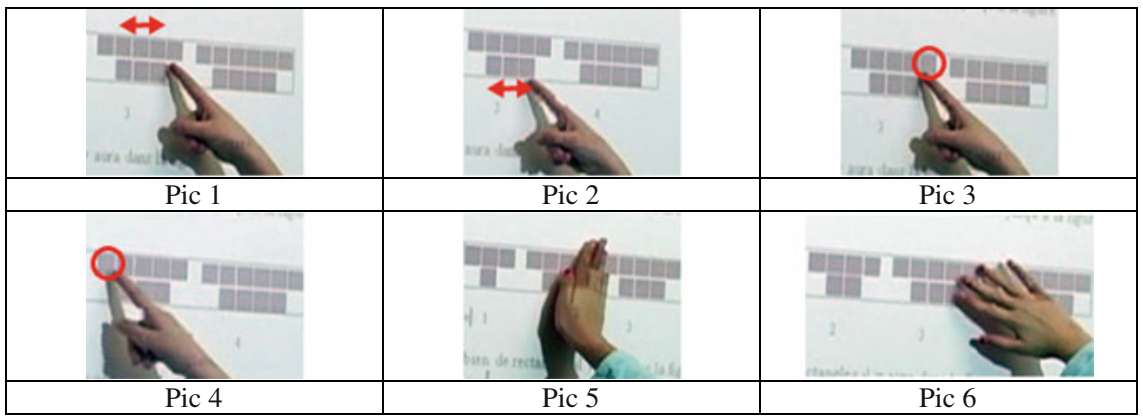

Fig. 11 Marianne's (Pic. 1-4) and Celia's (Pic. 5-6) gestures 


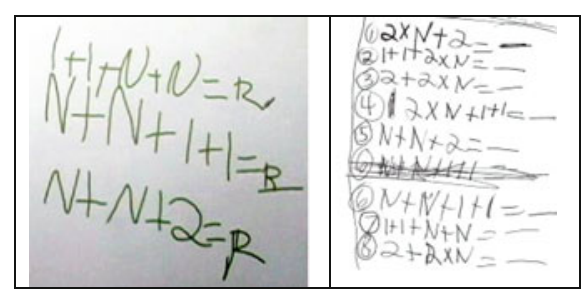

Fig. 12 Left, some formulas from the classroom discussion. Right, formulas from Erica's group

\section{Synthesis and Concluding Remarks}

In the first part of the article I suggested that algebraic thinking cannot be reduced to an activity mediated by notations. As I argued in previous work, a formula to calculate the number of rectangles in sequences like the one presented in Fig. 2, such as " $2 \mathrm{n}+1$," can be attained by arithmetic trial-and-error methods. Algebraic thinking, I suggested, is rather characterized by the analytic manner in which it deals with indeterminate numbers. A rigorous video analysis convinced us that students signify indeterminate numbers through recourse to a plethora of semiotic embodied resources that, rather than being merely a by-product of thinking, constitute the very sensible texture of it. From this sensuous perspective on human cognition, it is not difficult to appreciate that 7-8-year-old students can effectively start thinking algebraically. In the second part of the article I dealt with the question of the development of algebraic thinking. Algebraic thinking-like all cultural forms of thinking (e.g., aesthetic, legal, political, artistic) - is a theoretical form that has emerged, evolved and refined in the course of cultural history. It pre-existed in a developed ideal form before the students engaged in our classroom activities. The greatest characteristic of child development consists in how this ideal form exerts a real influence on the child's thinking. But how can this ideal form exert such an influence on the child? Vygotsky's answer is: under particular conditions of interaction between the ideal form and the child (1994). In our case, the particular conditions of interaction between algebraic thinking as a historical ideal form and our Grade 2 students were constituted by a sequence of activities that were intentional bearers of this ideal form. Naturally, the students cannot discern the theoretical intention behind our questions, as this cultural ideal form that we call algebraic thinking has still to be encountered and cognized. The lengthy, creative, and gradual processes through which the students encounter, and become acquainted with historically constituted cultural meanings and forms of (in our case algebraic) reasoning and action is what I have termed, following Hegel, objectification (Radford 2008b).

The objectification of ideal forms requires a temporal continuity and stability of the knowledge that is being objectified. The objectification of ideal forms requires also the mutual emotional and ethical engagement of teacher and students in the joint activity of teaching-learning (Radford and Roth 2011; Roth and Radford 2011). 
Drawing on the aforementioned idea of sensuous cognition and development, I suggested that the development of algebraic thinking can be studied in terms of the appearance of new systemic structuring relationships between the material-ideational components of thinking (e.g., gesture, inner and outer speech) and the manner in which these relationships are organized and reorganized in the course of the students' engagement in activity. The analysis of our experimental data focused on revealing those relationships and their progressive refinement. We saw how, for instance, the development of perception is consubstantial with the development of gestural and symbolic activity.

The whole story, however, is much more complex. As Vygotsky (1994) argued forcefully development can only be understood if we take into consideration the manner in which the student is actually emotionally experiencing the world. The emotional experience [perezhivanie] is, the Russian psychologist contended in a lecture given at the end of his life, the link between the subject and his/her surrounding, between the always changing subject (the perpetual being in the process of becoming) and his/her always conceptually, politically, ideologically moving societal environment. The explicit and meaningful insertion of perezhivanie into developmental accounts is, I suppose, still a trickier problem to conceptualize and investigate — an open research problem for sure.

Acknowledgments This article is a result of various research programs funded by the Social Sciences and Humanities Research Council of Canada (SSHRC/CRSH). I wish to thank Giorgio Santi and Chiara Andrà for their comments and suggestions on a previous version of this paper.

Open Access This chapter is distributed under the terms of the Creative Commons Attribution Noncommercial License, which permits any noncommercial use, distribution, and reproduction in any medium, provided the original author(s) and source are credited.

\section{References}

Arzarello, F., \& Edwards, L. (2005). Gesture and the construction of mathematical meaning. In Proceedings of the 29th PME conference (pp. 123-54). Melbourne: PME.

Bednarz, N, Kieran, C. \& Lee, L. (1996). Approaches to algebra. Perspectives for research and teaching. Dordrecht Boston London: Kluwer.

Cai, J., \& Knuth, E. (2011). Early algebraization. New York: Springer.

Carraher, D. W., \& Schliemann, A. (2007). Early algebra and algebraic reasoning. In F. K. Lester (Ed.), Second handbook of research on mathematics teaching and learning (pp. 669-705). Greenwich, CT: Information Age Publishing.

Descartes, R. (1954). The geometry. New York: Dover. (Original work published 1637)

Filloy, E., \& Rojano, T. (1989). Solving equations: The transition from arithmetic to algebra. For the Learning of Mathematics, 9(2), 19-25.

Filloy, E., Rojano, T., \& Puig, L. (2007). Educational algebra: A theoretical and empirical approach. New York: Springer Verlag.

Howe, R. (2005). Comments on NAEP algebra problems. Retrieved on $24.03 .12 \mathrm{http} / / / \mathrm{www}$. brookings.edu/ /media/Files/events/2005/0914_algebra/Howe_Presentation.pdf 
Kieran, C. (1989). A perspective on algebraic thinking. Proceedings of the 13th PME conference (v. 2, pp. 163-171). Paris: PME

Kieran, C. (1990). A procedural-structural perspective on algebra research. In F. Furinghetti (Ed.), Proceedings of the 15th PME conference (pp. 245-53). Assisi: PME.

Lakoff, G., \& Núñez, R. (2000). Where mathematics comes from. New York: Basic Books.

Mason, J. (1996). Expressing generality and roots of algebra. In N. Bednarz, C. Kieran, \& L. Lee (Eds.), Approaches to algebra (pp. 65-86). Dordrecht: Kluwer.

Radford, L. (2000). Signs and meanings in students' emergent algebraic thinking: A semiotic analysis. Educational Studies in Mathematics, 42(3), 237-268.

Radford, L. (2003). Gestures, speech and the sprouting of signs. Mathematical Thinking and Learning, 5(1), 37-70.

Radford, L. (2008a). Iconicity and contraction. ZDM - the International Journal on Mathematics Education, 40(1), 83-96.

Radford, L. (2008b). The ethics of being and knowing: Towards a cultural theory of learning. In L. Radford, G. Schubring, \& F. Seeger (Eds.), Semiotics in mathematics education (pp. 215-34). Rotterdam: Sense Publishers.

Radford, L. (2009a). "No! He starts walking backwards!” ZDM - the International Journal on Mathematics Education, 41, 467-480.

Radford, L. (2009b). Why do gestures matter? Sensuous cognition and the palpability of mathematical meanings. Educational Studies in Mathematics, 70(2), 111-126.

Radford, L. (2010). The eye as a theoretician: Seeing structures in generalizing activities. For the Learning of Mathematics, 30(2), 2-7.

Radford, L. (2011). Grade 2 students' non-symbolic algebraic thinking. In J. Cai \& E. Knuth (Eds.), Early algebraization (pp. 303-22). Berlin: Springer-Verlag.

Radford, L. (2012). On the development of early algebraic thinking. PNA, 6(4), 117-133.

Radford, L., \& Roth, W. -. (2011). Intercorporeality and ethical commitment. Educational Studies in Mathematics, 77(2-3), 227-245.

Radford, L., Bardini, C., \& Sabena, C. (2007). Perceiving the general. Journal for Research in Mathematics Education, 38, 507-530.

Roth, W. -, \& Radford, L. (2011). A cultural historical perspective on teaching and learning. Rotterdam: Sense Publishers.

Sutherland, R., Rojano, T., Bell, A., \& Lins, R. (2001). Perspectives on school algebra. Dordrecht: Kluwer.

Viète, F. (1983). The analytic art. New York: Dover. (Original work published 1591)

Vygotsky, L. S. (1987). Collected works (vol. 1). New York: Plenum.

Vygotsky, L. S. (1994). The problem of the environment. In V. d. Veer \& J. Valsiner (Eds.), The Vygotsky reader (pp. 338-54). Oxford: Blackwell. (Original work published 1934) 